Article

\title{
Expression of AtAAP Gene Family and Endosperm-Specific Expression of AtAAP1 Gene Promotes Amino Acid Absorption in Arabidopsis thaliana and Maize
}

\author{
Zhanyu Chen, Yingying Zhang, Jiating Zhang, Bei Fan, Ying Zhou and Xiyan Cui * \\ College of Life Sciences, Jilin Agricultural University, Changchun 130118, China; zhanyuc@jlau.edu.cn (Z.C.); \\ zhangyingying@alumni.jlau.edu.cn (Y.Z.); zhangjiating@mails.jlau.edu.cn (J.Z.); fanbei@alumni.jlau.edu.cn (B.F.); \\ yzhou@jlau.edu.cn (Y.Z.) \\ * Correspondence: cuixiyan@jlau.edu.cn
}

check for updates

Citation: Chen, Z.; Zhang, Y.; Zhang J.; Fan, B.; Zhou, Y.; Cui, X. Expression of AtAAP Gene Family and Endosperm-Specific Expression of AtAAP1 Gene Promotes Amino Acid Absorption in Arabidopsis thaliana and Maize. Agronomy 2021, 11, 1668. https://doi.org/10.3390/ agronomy11081668

Academic Editors: Fengjie Sun and Gustavo Caetano-Anollés

Received: 4 August 2021

Accepted: 19 August 2021

Published: 21 August 2021

Publisher's Note: MDPI stays neutra with regard to jurisdictional claims in published maps and institutional affiliations.

Copyright: (c) 2021 by the authors. Licensee MDPI, Basel, Switzerland. This article is an open access article distributed under the terms and conditions of the Creative Commons Attribution (CC BY) license (https:// creativecommons.org/licenses/by/ $4.0 /)$.
Abstract: The amino acid permease (AAP) is an important transmembrane protein that is involved in the absorption and transport of amino acids in plants. We investigated the expression patterns of AtAAP genes in Arabidopsis thaliana, based on quantitative real-time PCR. The results revealed differential expression patterns of eight AtAAP genes in different tissues, with five genes (AtAAP1, AtAAP2, AtAAP6, AtAAP7, and AtAAP8) expressed at relatively high levels in both flowers and siliques, suggesting their shared functions in the accumulation of amino acids. In transgenic plants, with endosperm-specific overexpression of AtAAP1, both AtAAP1 and AtAAP6 were up-regulated in both the roots and siliques, while AtAAP2, AtAAP3, AtAAP4, and AtAAP5 showed similar expression levels in the stems and siliques, whereas AtAAP7 and AtAAP8 were expressed at their highest levels in the stems and roots. The results of the amino acid affinity experiments revealed varied absorption capacities for different amino acids, by AtAAP1, and increased acid amino contents in the reproductive organs. These results were verified in transgenic maize plants, with the overexpression of $A t A A P 1$, revealing higher amino acid contents in the reproductive organs than those of the vegetative organs. Our study clearly demonstrated that the endosperm-specific promoter increased the amino acid contents in the reproductive organs and improved the effective utilization of organic nitrogen in plants.

Keywords: Arabidopsis thaliana; AAP gene family; gene expression; endosperm-specific promoter; transgenic maize

\section{Introduction}

Nitrogen plays an important nutritional role for many organisms, generally for the synthesis of hormones, nucleotides, and amino acids [1]. Plants are rich in usable forms of nitrogen, which are commonly found as organic nitrogen in amino acids, nucleic acids, and proteins. Studies have shown that inorganic nitrogen is obtained only through microbial mineralization that converts organic nitrogen in the soil [2]. Amino acids play important roles in plants. It is normally assumed that amino acids are probably the first group of metabolites produced by the organisms, and are consistently involved in many metabolic pathways in plants [3-5]. The transportation of amino acids into plant cells requires specific amino acid transporters. In Arabidopsis thaliana, there are approximately over 100 genes encoding amino acid transporters, which belong to the APC and UMATIT superfamilies [5]. The APC superfamily contains five families, i.e., the APC, the amino acid permease (AAP), the alanine and glycine protein cationic symporter (AGCS), the potassium ion and chloride ion transporters (CCC), and the hydroxy/aromatic amino acid permease (HAAAP) families. As the two widely studied families of the APC superfamily, the APC family includes the cationic amino acid transporters (CATs), the amino acid/choline transporters (ACTs), and the polyH transporters (PHSs), while the AAAP family contains the amino acid 
permeases (AAPs), the lysine and histidine transporters (LHTs), the proline transporters (ProTs), the auxin transport protein (AUXs), and the aromatic and neutral amino acid transporters (ANTs). The results of genomic comparative analyses revealed that the amino acid transporters are widely distributed in plants, with increasing evidence clearly demonstrating that the amino acid transporters function in diverse ways [6]. However, the physiological functions of these amino acid transporters remain unclear.

Members of the AAP family have been identified in many organisms, including fungi, animals, and plants [7-9]. Due to the important functions that these amino acid transporters play in plant growth and development, the studies of the substrate specificity, localization of expression, and biological functions of the AAP family members have attracted increasing attention. The AAP family is involved in a variety of physiological activities in plants, such as the absorption of amino acids from the soil, loading of amino acids to the phloem, transportion of amino acids between the xylem and phloem, and accumulation of seed storage proteins [10]. Studies have suggested that the AAPs extensively transport amino acids with low affinity, based on the heterologous expression of AAPs in Saccharomyces cerevisiae mutants and Xenopus oocytes that are deficient in endogenous transportation systems [11,12]. Specifically, AAP1 is demonstrated to preferentially transport neutral amino acids in yeast cells and in Xenopus oocytes [13]. Although the transporting properties and substrate specificity of AAPs have been characterized, based on the heterologous expression analysis, the physiological functions of these amino acid transporters remain unclear in plants [14]. It has been reported that changes in the corresponding transcript levels occur in response to biotic stresses, such as nematode wounding, pathogenic attack, or interaction with mycorrhizal fungi, mostly affecting the nitrogenous compounds, while the plants make full use of their own transporters, to retain and redistribute these compounds [15,16]. For example, studies have shown that three genes (i.e., BnAAP1, BnAAP2, and BnAAP6) are up-regulated in the flowers of Brassica napus, under high-nitrogen conditions, whereas $V F A A P 1$ is down-regulated in the presence of high concentrations of glutamine and sucrose, or $1 \mathrm{mmol} / \mathrm{L}$ cysteine $[17,18]$. In A. thaliana, two genes (i.e., AtAAP3 and AtAAP6) are involved in the nematode infestation of root-knot, while the corresponding activities are significantly reduced in the aap 3 and aap 6 mutants $[19,20]$. The overexpression of VfAAP1 in seeds increases the amount of storage proteins, while reduced or increased expression of LHT1 suggests its involvement in absorbing amino acids into the root and mesophyll cells [21-23]. These results are consistent with those reported previously, suggesting that the increased uptake and reallocation of neutral amino acid, via OsAAP1, improves the growth and enhances the grain yield in rice [24].

The AAP family was first described in A. thaliana, containing eight members (i.e., AtAAP1 to AtAAP8), encoding proteins located on the cytoplasmic membrane, with AtAAP7 on the chloroplast $[25,26]$. The AAP gene family is involved in functions such as $\mathrm{H}^{+}$-coupled amino acid absorption. Specifically, the ratio of AAP coordinated transport of protons and amino acids into cells is 1:1, while the results of hydrophilicity analysis predict that the AAP protein contains a total of 10-12 transmembrane domains [27,28].

In this study, we investigated the expression patterns of eight $A A P$ genes (i.e., AtAAP1 to $A t A A P 8$ ) in the roots, stems, leaves, flowers, and siliques, of both wild-type (WT) and transgenic plants of $A$. thaliana, using quantitative real-time PCR (qRT-PCR) analysis. Our goals were to (1) reveal the relationship between the tissue-specific expression of the eight AtAAP genes in A. thaliana, and the amino acid indices of WT and transgenic plants, including the contents of free amino acid, total nitrogen, and 20 types of amino acids; and to (2) significantly increase the amino acid contents in plant organs, by overexpressing AtAAP1 in both the transgenic plants of $A$. thaliana and maize. Our study provides strong evidence to support the improvement of the effective utilization of organic nitrogen by crops. 


\section{Materials and Methods}

\subsection{AtAAP1 Transgenic Arabidopsis thaliana and Maize}

The endosperm-specific plant expression vector PTF101.1-GT1-AtAAP1 was constructed by ligating the target gene AtAAP1, the plant expression vector PTF101.1, and the endosperm-specific promoter GT1, as previously reported [29]. The PTF101.1-GT1-AtAAP1 was transferred into Agrobacterium by the triparental hybridization method, to obtain the recombinant plasmid of Agrobacterium, which was verified by double enzyme digestion. Specifically, the GT1 promoter sequence was digested with BamHI and HindIII, while the AtAAP1 gene sequence was digested with Sma I and Sac I (Figure 1). The plant expression vector PTF101.1-GT1-AtAAP1 was transformed into Arabidopsis thaliana (Columbia Col-0) and maize (Zea mays L. var. B73) by the Agrobacterium-mediated transformation. After two generations of screening, the T2 generation of transgenic $A$. thaliana and maize with overexpression of AtAAP1 were obtained for further experiments.

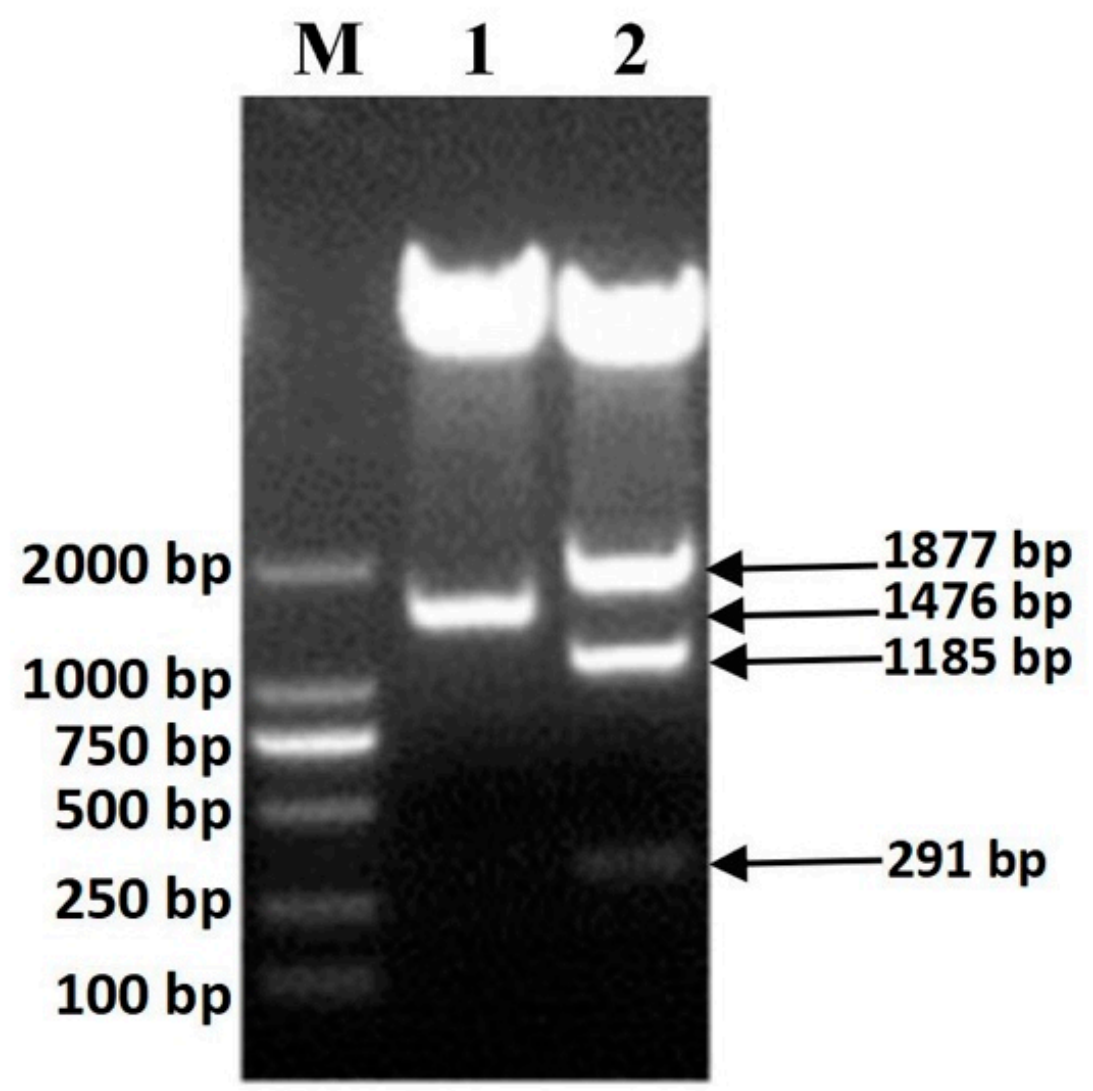

Figure 1. Construction of the endosperm-specific plant expression vector PTF101.1-GT1-AtAAP1 based on triparental hybridization method. Lane M represents the DL2000 DNA marker. Lane 1 represents the AtAAP1 gene sequence (1476 bp) derived from the double digestion of PTF101.1-GT1AtAAP1 by Sma I and Sac I. Lane 2 represents the GT1 promoter sequence (1877 bp) derived from the double digestion of PTF101.1-GT1-AtAAP1 by BamHI and HindIII. The fragments of $1185 \mathrm{bp}$ and $291 \mathrm{bp}$ were derived from the double digestion of AtAAP1 gene sequence by BamHI and HindIII.

Plants of A. thaliana were grown in the artificial climate chamber in the College of Life Sciences at Jilin Agricultural University (Changchun, China). Seeds were submerged in pure water at $4{ }^{\circ} \mathrm{C}$ for two days and then planted in pots containing a mixture of vermiculite $(70 \%)$ and soil $(30 \%)$. In two weeks, each seedling was transferred into a single pot. Plants were grown in an environmentally controlled growth chamber with a photoperiod cycle of $16 \mathrm{~h}$ light $\left(20^{\circ} \mathrm{C}\right)$ and $8 \mathrm{~h}$ dark $\left(16^{\circ} \mathrm{C}\right)$. In six weeks, plant materials were collected, including vegetative organs (i.e., roots, stems, and leaves) and reproductive organs (i.e., flowers and siliques). Non-transgenic plants of $A$. thaliana were used as the control. 
The negative and positive seeds of transgenic maize plants were identified as follows. Specifically, several transgenic corn seeds were ground into powder in liquid nitrogen, to extract total RNA using the TaKaRa MiniBEST plant RNA extraction kit (Takara Biotechnology Co., Ltd., Dalian, China). The RNA was reverse-transcribed to synthesize cDNA using the PrimeScript RT reagent kit with gDNA Eraser (Takara Biotechnology Co., Ltd., Dalian, China), which was used to perform PCR amplification based on the primers used for cloning the AtAAP1, i.e., forward primer 5'-CCCCCGGGATGAAGAGTTTCAACACAG AAGGAC-3' ${ }^{\prime}$ and reverse primer 5'-CGAGCTCTCACTCATGCATAGTCCGGAAG-3' . Positive and negative seeds were identified based on the presence and absence of the AtAAP1 gene, respectively (Figure 2). The transgenic corn plants were grown in the Transgenic Pilot Test and Industrialization Base of the Jilin Academy of Agricultural Sciences (Gongzhuling, Changchun, China). During the mature stage, the samples of roots, leaves, and seeds were collected by liquid nitrogen freezing. The negative plants were used as controls.

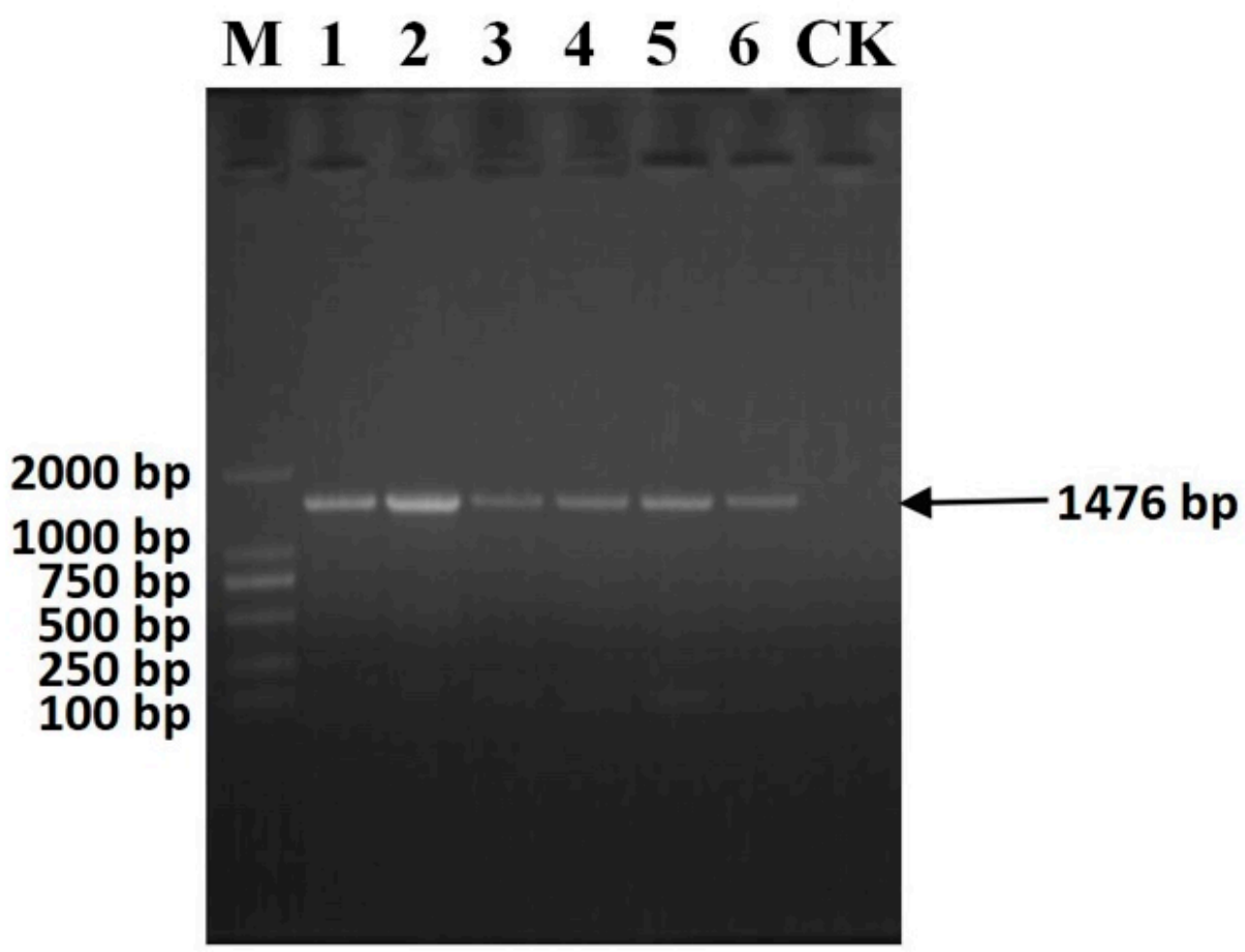

Figure 2. Identification of negative and positive seeds of transgenic maize plants with overexpression of AtAAP1. Lane M represents the DL2000 DNA marker. Lanes 1-6 represent positive seeds of transgenic maize plants with the overexpression of AtAAP1 gene (1476 bp). CK represents the negative seed of transgenic maize plant (showing no presence of AtAAP1).

\subsection{Measurement of Physiological Indices}

\subsubsection{Contents of Amino Acid and Total Nitrogen}

Contents of free amino acids were determined using the ninhydrin methods [30]. The total nitrogen contents were determined by the Kjeldahl methods [31] using a Kjeltec TM8200 semi-automatic Kjeldahl determination unit with the matching boiling tubes and elimination furnace, obtained from FOSS Technology \& Trading Co., Ltd. (Beijing, China). Solutions prepared included $\mathrm{NaOH}$ solution $(0.4 \mathrm{~g} / \mathrm{mL}), \mathrm{H}_{3} \mathrm{BO}_{3}$ indicator solution $(10 \mathrm{~g} / \mathrm{L})$, $\mathrm{H}_{2} \mathrm{SO}_{4}$ titrant $(0.01 \mathrm{~mol} / \mathrm{L}), 30 \% \mathrm{H}_{2} \mathrm{O}_{2}$ (analytical grade), and mixed indicator solutions of methyl red and bromocresol green.

The contents of 20 amino acids in transgenic plants of $A$. thaliana and maize plants at their mature stages were determined by high-performance liquid chromatographyquadrupole ion trap tandem mass spectrometry (HPLC-MS/MS API3200 Q-TRAP, Applied Biosystems China Co., Beijing, China). Fresh plant materials of five tissues (i.e., roots, stems, 
leaves, flowers, and siliques) were sheared and dried at $-80{ }^{\circ} \mathrm{C}$, and then ground into powder. An aliquot of $\sim 100 \mathrm{mg}$ of powder of each tissue was placed in a $2 \mathrm{~mL}$ centrifuge tube and shipped to the Pury Huasheng Biotechnology Company (Beijing, China) for further processing. Each experiment was repeated thrice.

\subsubsection{Preparation of Murashige and Skoog (MS) Medium Containing Amino Acids}

Plant growth is generally inhibited by high concentrations of amino acids [32,33]. Therefore, we investigated the affinity of AtAAP1 for the 20 types of amino acids, with various concentrations determined based on previous studies [32,33] (Table 1). To make the Murashige and Skoog (MS) medium, both $2.22 \mathrm{~g}$ MS powder and $10 \mathrm{~g}$ sucrose were dissolved in $800 \mathrm{~mL}$ distilled water with the constant volume adjusted to $1 \mathrm{~L}$. A total of $20 \mathrm{~mL}$ of the MS medium solution was added into each of 21 triangular $100 \mathrm{~mL}$ vials, each containing one of the 20 types of amino acids (Table 1), including 1 vial of control without amino acid, stirred well and the $\mathrm{pH}$ adjusted to 5.8 with $1 \mathrm{~mol} / \mathrm{L} \mathrm{KOH}$ or $1 \% \mathrm{HCl}$. Finally, $0.15 \mathrm{~g}$ agarose was added to each of these 21 vials. After sterilization at $115^{\circ} \mathrm{C}$ for $30 \mathrm{~min}$, the medium solution was poured into the Petri dishes on the ultra-clean bench. Each experiment was repeated thrice.

Table 1. Amino acid concentrations in the Murashige and Skoog (MS) medium used in the amino acid affinity experiments of transgenic Arabidopsis thaliana.

\begin{tabular}{cc}
\hline Amino Acid & Concentration (mmol/L) \\
\hline Phe, Trp, Tyr, Lys & 1 \\
Gly & 1.5 \\
Met, Ile, Leu, Ser, Thr & 2 \\
His & 2.5 \\
Val & 4 \\
Cys, Asn, Arg & 5 \\
Ala & 10 \\
Gln, Asp & 20 \\
Pro, Glu & 30 \\
\hline
\end{tabular}

\subsubsection{Amino acid Affinity in Transgenic Arabidopsis thaliana}

Seeds of $A$. thaliana were disinfected in $2 \%$ sodium hypochlorite solution for $10 \mathrm{~min}$, and then washed with sterile water 5 times. The seeds were planted on MS medium, each containing one of the 20 types of amino acids, by micropipettes $(200 \mu \mathrm{L})$. The medium was divided into two equal halves, with each side planted with 9 seeds of WT A. thaliana and 9 T2 seeds of transgenic $A$. thaliana, respectively. The growth of $A$. thaliana was observed in the Petri dishes for a total of 15 days.

\subsection{Quantitative Expression Analysis}

Plants of $A$. thaliana were harvested after $\sim 45$ days of growth for RNA extraction. Total RNA was isolated from different tissues of $\mathrm{WT}$ and transgenic plants with overexpression of AtAAP1, using the plant RNA extraction kit (Takara, Japan) as previously described [34]. Genomic DNA contamination was avoided by treating the extracted RNA samples with the DNase provided in the RNA extraction kit. The cDNAs were synthesized using $1 \mu \mathrm{g}$ of RNA. Based on the DNA sequences of the eight AtAAP genes and the actin gene obtained from the National Center for Biotechnology Information (NCBI) database, the primers were designed by using the Primer Premier 5.0 software for the quantitative expression analysis based on qRT-PCR (Table 2). The actin gene of $A$. thaliana was used as the internal reference gene in the quantitative expression analysis. To avoid the potential effects of genomic DNA contamination, these primers were designed to span intron-splicing sites. The qRT-PCR analysis was performed using a Stragene Mx3000P (Agilent Technologies, Beijing, China) with the following procedures: denaturation for $3 \mathrm{~min}$ at $95^{\circ} \mathrm{C}$, followed by 45 cycles of denaturation of $10 \mathrm{~s}$ at $95^{\circ} \mathrm{C}$ and annealing/extension for $1 \mathrm{~min}$ at $60^{\circ} \mathrm{C}$. Each 
$20 \mu \mathrm{L}$ PCR reaction contained $10 \mu \mathrm{L}$ of SYBR Green (Genecopoeia, Beijing, China), $7.6 \mu \mathrm{L}$ of $\mathrm{ddH}_{2} \mathrm{O}, 1 \mu \mathrm{L}$ of each cDNA product, $0.4 \mu \mathrm{L}$ of ROX reference dye II, and $0.5 \mu \mathrm{L}$ of each of the two primers. Relative gene expression levels were determined in WT and transgenic plants according to the $2^{-\Delta \mathrm{CT}}$ and $2^{-\Delta \Delta \mathrm{CT}}$ methods [35], respectively. The $\Delta \mathrm{CT}$ and $\Delta \Delta \mathrm{CT}$ were calculated using the formulas $\Delta \mathrm{CT}=\mathrm{CT}_{\text {target }}-\mathrm{CT}_{\text {control }}$ and $\Delta \Delta \mathrm{CT}=\Delta \mathrm{CT}_{\text {treated sample }}$ $-\Delta \mathrm{CT}_{\text {untreated sample, }}$ respectively. All experiments were repeated three times based on three independently grown sets of plants from a sample pool of more than 15 plants. The quantitative expression analysis was performed based on corn plants at milk, dough, and mature stages in three lines of AtAAP1-positive plants (i.e., KF8-5, KF8-17, and KF8-40), as described above for Arabidopsis.

Table 2. DNA sequences of primers used for the quantitative expression analysis based on the quantitative real-time PCR (qRT-PCR) of eight AtAAP genes and the internal reference gene actin in Arabidopsis thaliana.

\begin{tabular}{|c|c|c|}
\hline Gene & GenBank Accession & Forward (F) and Reverse (R) Primers $5^{\prime}-3^{\prime}$ \\
\hline \multirow{2}{*}{ AtAAP1 } & \multirow{2}{*}{ NM_104616 } & F: GTGGGAAAGTGGGTAAGACG \\
\hline & & R: GATGAGAACCGTGGCATAAG \\
\hline \multirow{2}{*}{ AtAAP2 } & \multirow{2}{*}{ NM_120958 } & F: ATAACCACCGTCACCACCAC \\
\hline & & R: GGTCCAAACAGTCCCAGTTC \\
\hline \multirow{2}{*}{ AtAAP3 } & \multirow{2}{*}{ NM_106387 } & F: CGCCGTTATGTCCTTCACTT \\
\hline & & R: TGCTCCTATGCTAATCCCAGT \\
\hline \multirow{2}{*}{ AtAAP4 } & \multirow{2}{*}{ NM_125780 } & F: CCCATCTTCGCCTTTATTGA \\
\hline & & R: CACAAACCCGCTTCGGTA \\
\hline \multirow{2}{*}{ AtAAP5 } & \multirow{2}{*}{ NM_103536 } & F: GATTGGTTGGATTGGTGGTC \\
\hline & & R: CCGAGGTTGGAGTGAATAGC \\
\hline \multirow{2}{*}{ AtAAP6 } & \multirow{2}{*}{ NM_124341 } & F: GCAAACGCAACTACACCTACA \\
\hline & & R: GACCTCTTCACTGCCACCAT \\
\hline \multirow{2}{*}{ AtAAP7 } & \multirow{2}{*}{ NM_122286 } & F: ACGGGAGTGGCAGTGATGT \\
\hline & & R: ACAGACGAGCAAGCACACAA \\
\hline \multirow{2}{*}{ AtAAP8 } & \multirow{2}{*}{ NM_100875 } & F: ATGGCCTCAAAGCAATTTCA \\
\hline & & R: GCATGTCCTCCAAACCAGTC \\
\hline \multirow{2}{*}{ actin } & \multirow{2}{*}{ NM_180280 } & F: TGCCAATCTACGAGGGTTTC \\
\hline & & R: GCTCTGCTGTTGTGGTGAAC \\
\hline
\end{tabular}

\subsection{Data Analysis}

All data were presented as the mean of three biological replicates \pm standard deviation (SD). One-way ANOVA using DPS 11.0 edition for windows was conducted to identify the significant difference between the treatments with the $p$ values set to 0.01 or 0.05 , respectively [36].

\section{Results}

\subsection{Expression Patterns of AtAAP Genes}

To explore the functions of AtAAP genes, the expression patterns of eight AtAAP genes, in different tissues of mature plants of WT A. thaliana, were investigated, based on qRTPCR analysis (Figure 3). All eight genes showed differential patterns in different tissues. Specifically, four genes (i.e., AtAAP2, AtAAP3, AtAAP6, and AtAAP7) were relatively highly expressed in leaves, flowers, and siliques, two genes (AtAAP1 and AtAAP8) were relatively highly expressed in flowers and siliques, gene AtAAP4 was highly expressed in stems, and gene AtAAP5 showed relatively high expression in both leaves and flowers. 

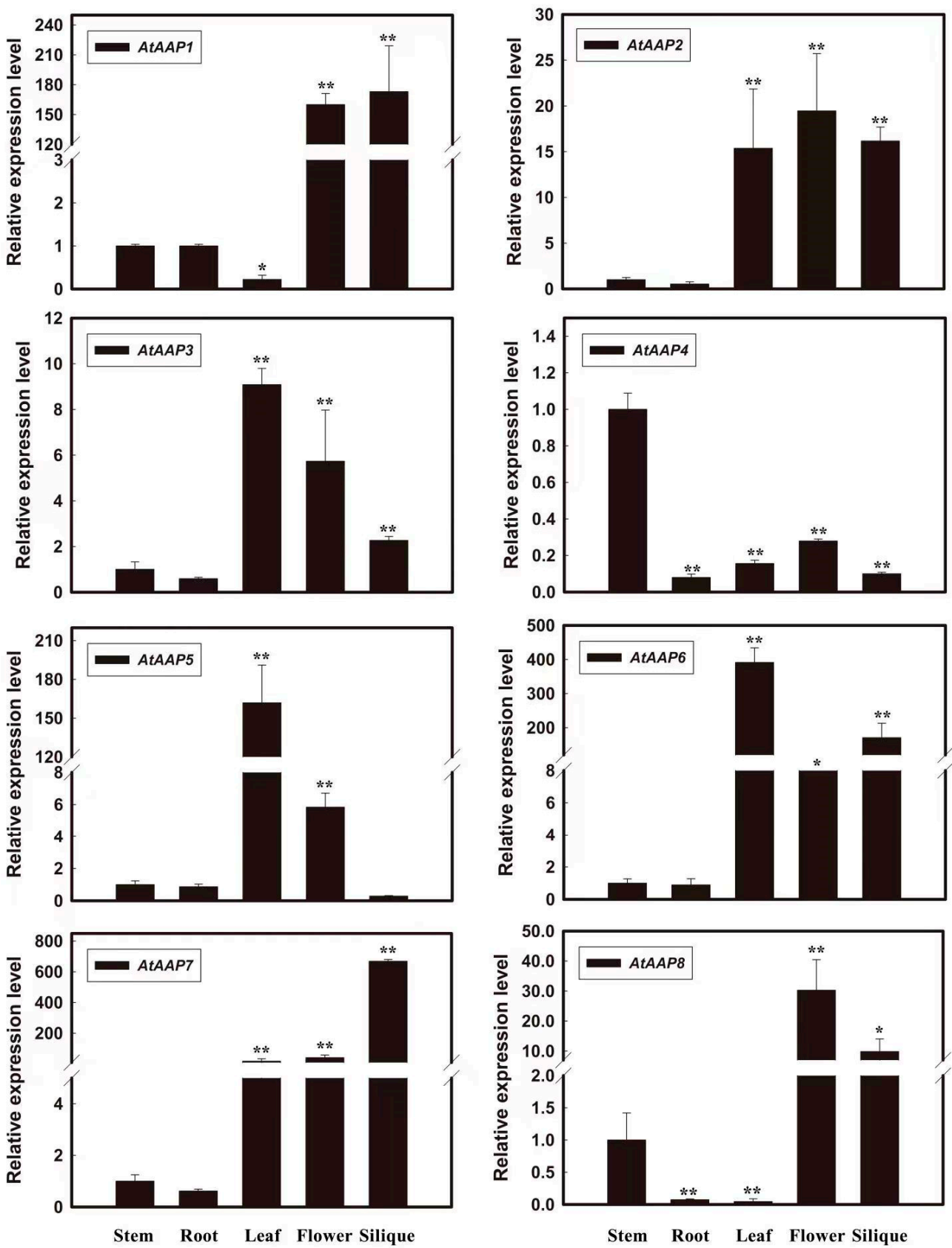

Figure 3. Relative expression patterns of eight AtAAP genes in different tissues of wild-type (WT) Arabidopsis thaliana based on qRT-PCR analysis with actin gene as the internal reference gene. Symbols "*" and "*** indicate the significant differences in comparison to stems at $p$ values of 0.05 and 0.01 , respectively.

To compare the expression patterns and functions of AtAAP genes in amino acid transport, in both WT and transgenic plants with overexpression of $A t A A P 1$, we further investigated the expression patterns of $A t A A P$ genes in transgenic plants of $A$. thaliana, with overexpression of AtAAP1 (Figure 4). The results showed that eight AtAAP genes were differentially up- and down-regulated in various tissues of transgenic plants with overexpression of AtAAP1, with three expression patterns identified. First, both AtAAP1 and $A t A A P 6$ showed relatively higher expressions in both the roots and siliques than that in the stems, with AtAAP1 being up-regulated by 25 times and 20 times in the siliques and roots of transgenic $A$. thaliana, respectively. Second, four genes (i.e., AtAAP2, AtAAP3, 
AtAAP4, and AtAAP5) showed relatively high expression in the stems and siliques. Third, AtAAP7 and AtAAP8 were highly expressed in the stems and roots.
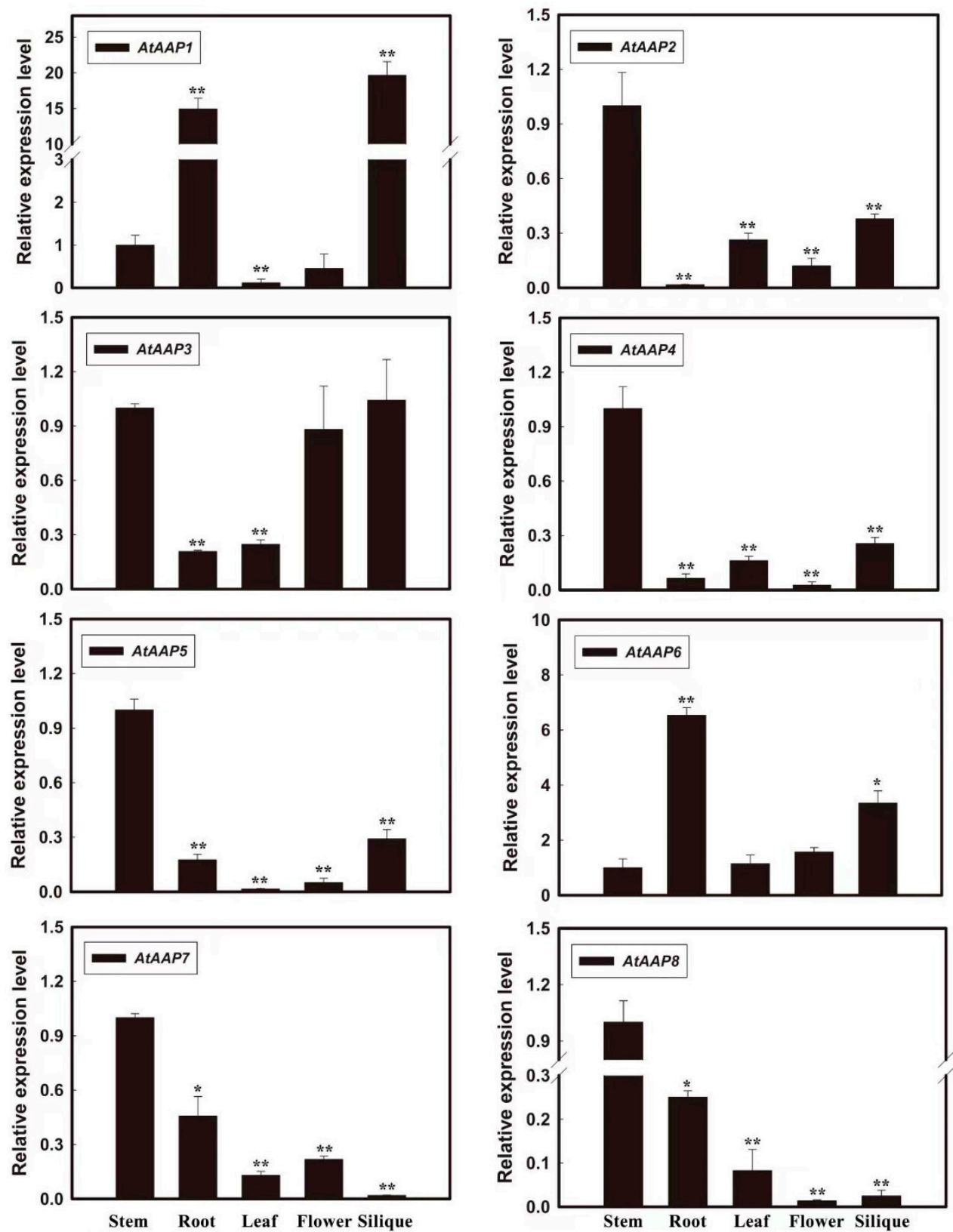

Figure 4. Relative expression patterns of eight AtAAP genes in different tissues of transgenic Arabidopsis thaliana with overexpression of AtAAP1 based on qRT-PCR analysis using actin gene as the internal reference gene. Symbols "** and "***" indicate significant differences in comparison to stems at $p$ values of 0.05 and 0.01 , respectively.

3.2. Contents of Total Nitrogen and Free Amino Acids in Reproductive and Vegetative Organs in WT and Transgenic Plants of Arabidopsis thaliana with Overexpression of AtAAP1

Compared to the WT plants, the transgenic plants of $A$. thaliana, with overexpression of AtAAP1, showed a significantly decreased (by $\sim 65 \%$ ) total nitrogen content in the vegetative organs, by $\sim 65 \%$, but increased by $\sim 29 \%$ in the reproductive organs (Figure $5 \mathrm{~A}$ ). In comparison to the WT plants, the transgenic plants showed significantly increased free amino acid contents in the reproductive organs, by $\sim 34 \%$, and in vegetative organ, by $\sim 12 \%$ (Figure 5B). 

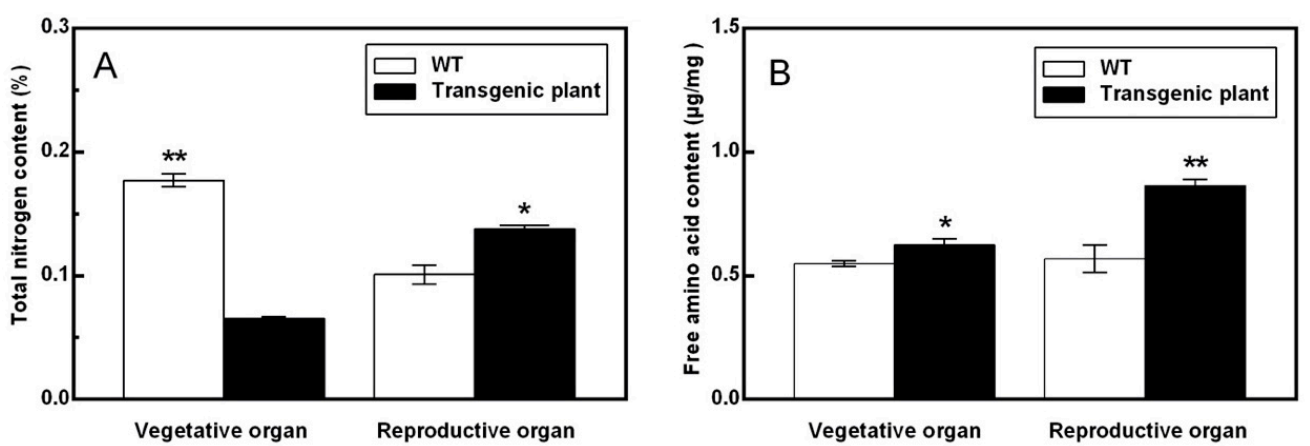

Figure 5. Contents of total nitrogen (A) and free amino acids (B) in vegetative (roots, and stems, and leaves) and reproductive (flowers and siliques) organs of wild-type (WT) and transgenic plants of Arabidopsis thaliana with overexpression of AtAAP1. Symbols "*" and "***" indicate significant differences at $p$ values of 0.05 and 0.01 , respectively.

\subsection{Contents of Free Amino Acids in WT and Transgenic Plants of Arabidopsis thaliana with Overexpression of AtAAP1}

To explore the functions of the AtAAP genes, and the potential relationships between each $A t A A P$ gene and the transportation of the 20 types of amino acids, the composition and concentration of single amino acids in different organs of WT and transgenic $A$. thaliana, with overexpression of AtAAP1, were determined based on HPLC analysis (Figure 6). The distributions of single amino acids largely varied in different tissues. The contents of Gly, Val, Ile, Pro, Phe, Thr, Gly, Cys, Asn, and Gln were relatively high, while the contents of His, Ala, Ser, and Tyr were relatively low, probably due to the involvement of these amino acids in sugar metabolism. The contents of Ile and Val were the highest in the roots and siliques (Figure 6A,E), the contents of Thr and Cys were the highest in the stems and flowers (Figure 6B,D), and the contents of Thr and Gly were the highest in the leaves (Figure 6C). Glu was not detected in any organs of the plants, while Tyr was not detected in the roots (Figure 6A) and His was not detected in the leaves and roots (Figure 6A,C). In WT plants, four amino acids (i.e., Val, Thr, Gly, and Cys) were detected at high levels in both the stems and leaves (Figure 6B,C), while Ile and Val were detected at high levels in the roots and siliques, respectively (Figure 6A,E). In transgenic plants, the total amino acid content was the highest in the flowers (Figure 6D) and the lowest in the roots (Figure 6A). The contents of 20 amino acids in transgenic plants were lower than those of the WT in the vegetative organs (i.e., roots, stems, and leaves), while the contents of 10 amino acids (i.e., Met, Val, Pro, Phe, Trp, Thr, Gly, Asp, Lys, and Arg) were higher in the flowers of the WT than those in the transgenic plants, and the contents of many amino acids were higher in the transgenic plants than those of the WT in the siliques (Figure 6E).

\subsection{Affinity of 20 Amino Acids in Transgenic Arabidopsis thaliana with Overexpression of AtAAP1}

Under the selected concentrations of the 20 amino acids (Table 1), the growth of the WT plants of $A$. thaliana was either normal or slightly inhibited, whereas the growth of the transgenic plants was inhibited, with the transgenic plants showing affinity for the amino acid added into the MS medium (Figure 7). The results showed that both the WT and transgenic plants grew normally in the control group. On the MS medium containing neutral amino acids, most of the transgenic plants either did not germinate or germinated, but grew to wilt, while the WT plants were slightly inhibited. Specifically, AtAAP1 showed a strong affinity for most neutral amino acids, including aromatic amino acids (Phe and Tyr), amides (Asn and Gln), Ala, Ile, Leu, Val, Ser, Thr, and Cys, but a low or no affinity for Arg, Lys, Met, Gly, and Pro. 

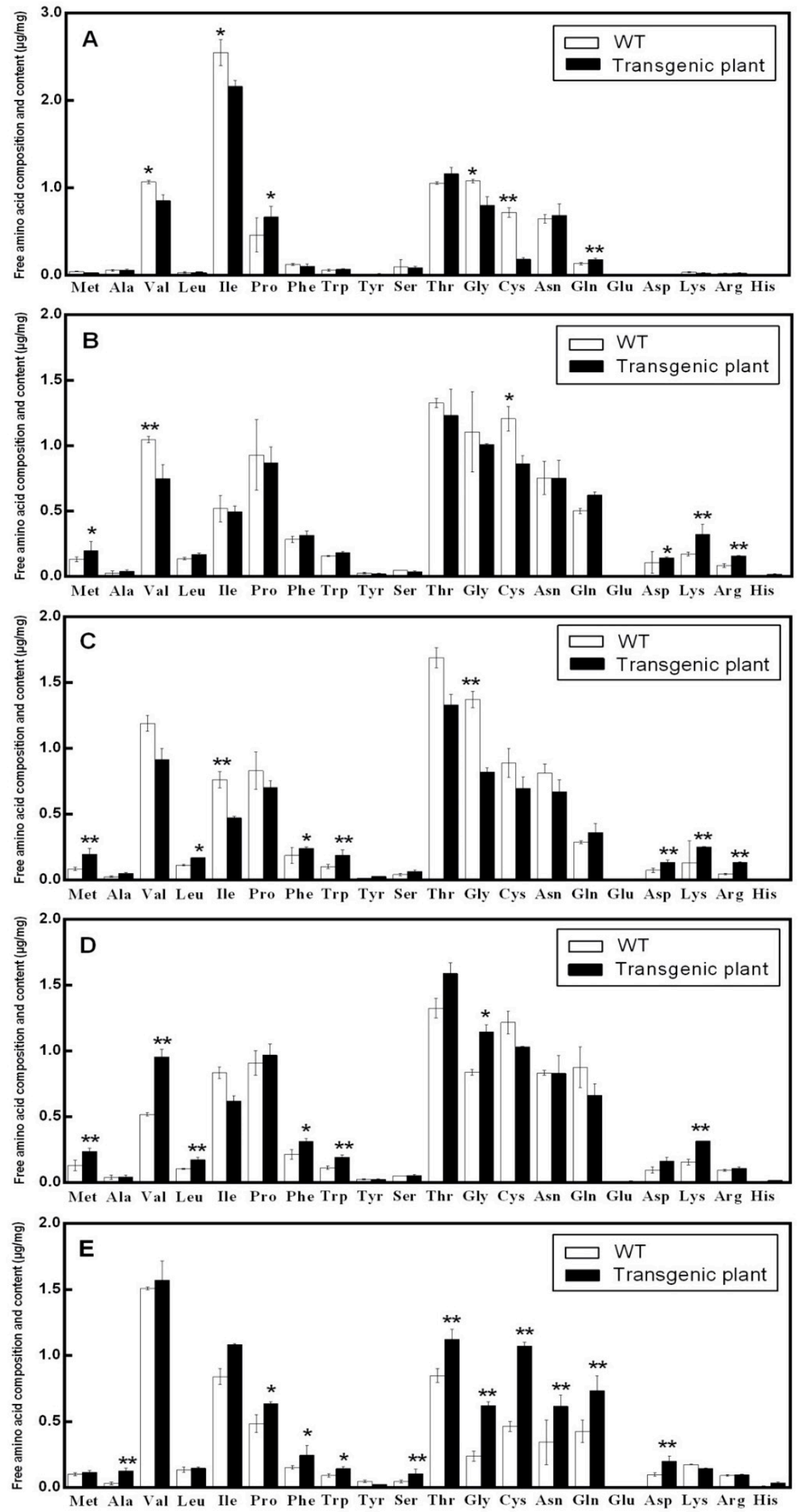

Figure 6. Contents of 20 amino acids in roots (A), stems (B), leaves (C), flowers (D), and siliques (E) of wild-type (WT) and transgenic plants of Arabidopsis thaliana with overexpression of AtAAP1. Symbols "*" and "**" indicate significant differences at $p$ values of 0.05 and 0.01 , respectively. 

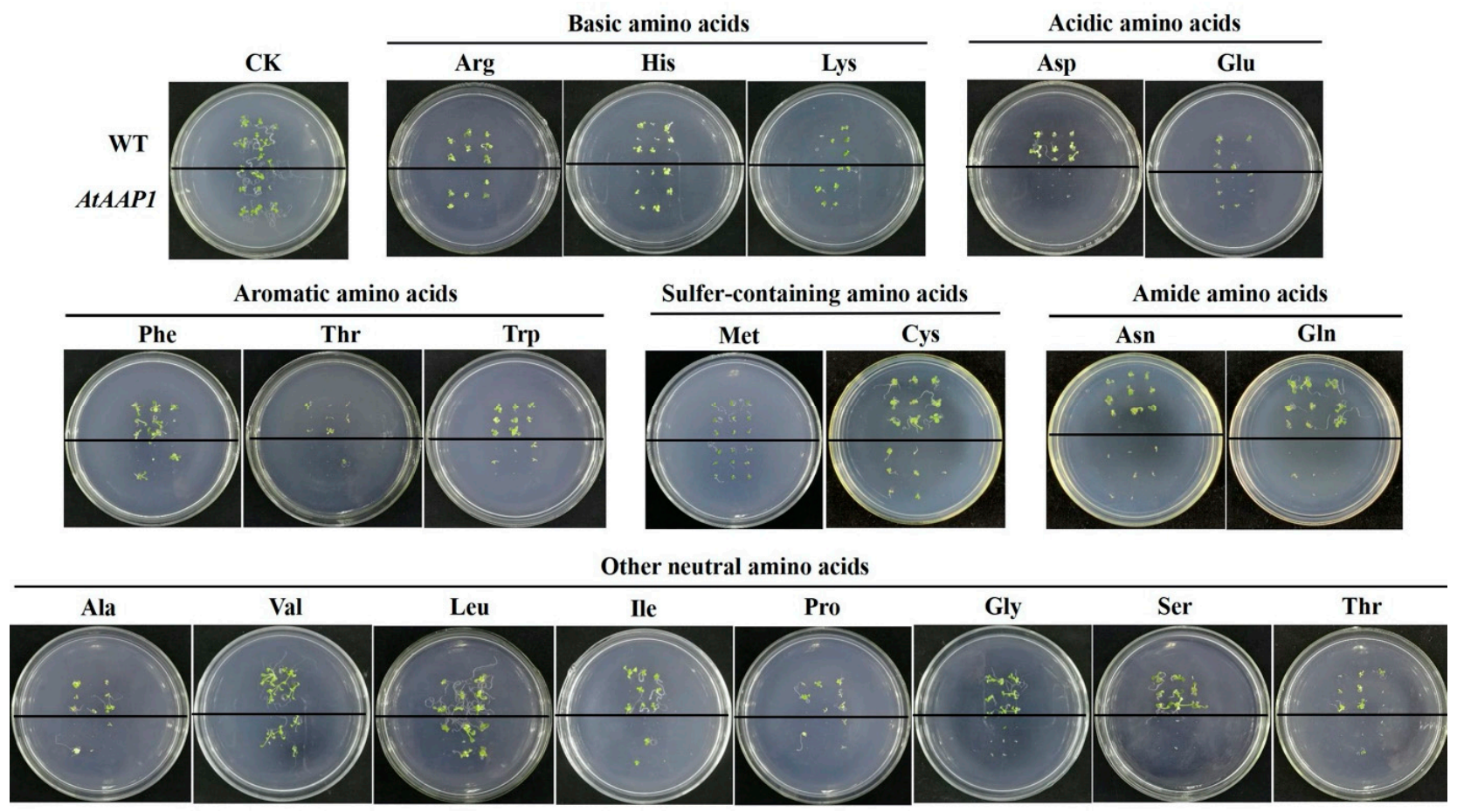

Figure 7. Affinity of 20 amino acids in wild-type (WT) and transgenic plants of Arabidopsis thaliana with overexpression of AtAAP1. CK is the control MS medium without any amino acid in the medium.

\subsection{Gene Expresion of AtAAP1 in Transgenic Maize with the Endosperm-Specific Promoter}

The results of the relative expression of AtAAP1 in the seeds of transgenic corn plants, at milk, dough, and mature stages, showed that the expression of AtAAP1 in postive maize was significantly increased in comparison to that of the negative maize plants, with the lowest expression level being observed at the milk stage and highest expression levels revealed at both the dough and mature stages (Figure 8).

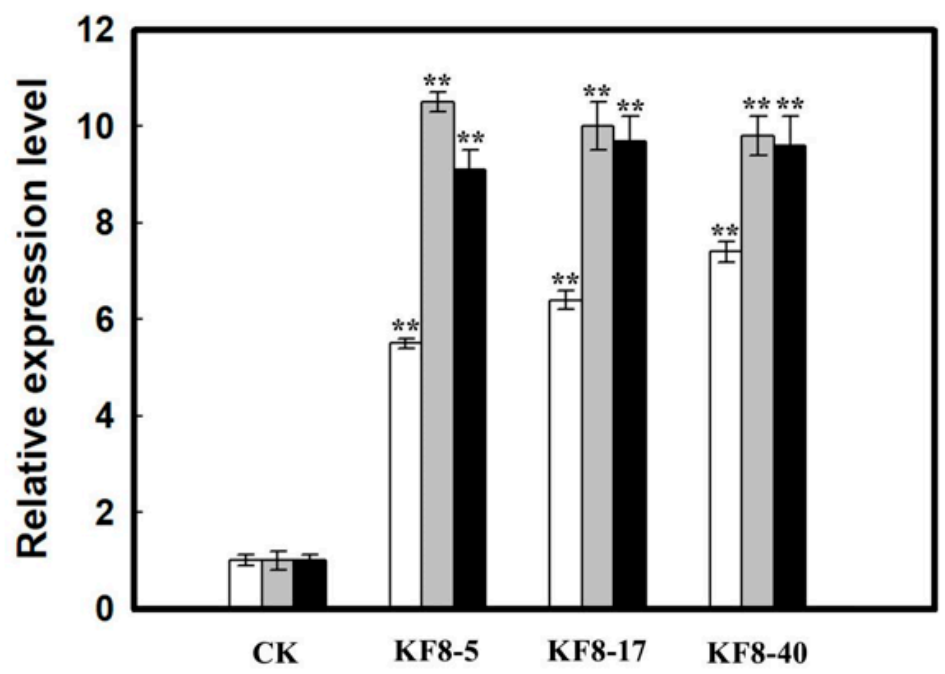

Figure 8. Relative expression of AtAAP1 gene in three lines (i.e., KF8-5, KF8-17, and KF8-40) of transgenic maize plants with overexpression of AtAAP1 at milk (white bars), dough (gray bars), and mature (black bars) stages based on qRT-PCR analysis using actin gene as the internal reference gene. Symbol "**" indicates significant differences in comparison to negative maize plants (CK) at $p$ value of 0.01 . 


\subsection{Contents of 20 Amino Acids in Different Tissues of Transgenic AtAAP1 Maize with the Endosperm-Specific Promoter}

To investigate the effects of the AtAAP1 gene on the absorption of amino acids in crops, we investigated the contents and compositions of 20 amino acids in different tissues of positive and negative maize plants, with the endosperm-specific promoter, based on HPLC (Table 3). The results showed that the contents of total and neutral amino acids in the roots and seeds of positive plants, were higher than those of the negative plants, while the contents of basic and acidic amino acids were higher in the roots and lower in the leaves of positive plants than those of the negative plants. During the mature stage of transgenic AtAAP1 maize plants, the amino acid contents of the reproductive organs were generally higher than those of the vegetative organs. These results in maize were consistent with those derived above in the transgenic plants of $A$. thaliana. Compared with the negative plants, the contents of eight amino acids (i.e., Arg, Lys, Glu, Ile, Leu, Met, Thr, and Val) and six amino acids (i.e., His, Phe, Ile, Trp, Tyr, and Val) were higher in the roots and seeds of the positive plants, respectively, while the contents of 12 amino acids (i.e., Lys, Asp, Glu, Phe, Gln, Asn, Ala, Ile, Leu, Pro, Ser, and Val) were lower in the leaves of the positive plants than those in the negative plants. These results were comparable with those of $A$. thaliana (Figure 6A,C,E).

Table 3. Contents of 20 amino acids in different tissues of transgenic AtAAP1 maize plants with the endosperm-specific promoter. Data are presented in negative/positive plants. Symbols "*" and "**" indicate significant differences at $p$ values of 0.05 and 0.01 , respectively.

\begin{tabular}{|c|c|c|c|}
\hline Amino Acid & Roots $(\mu \mathrm{g} / \mathrm{mg})$ & Leaves $(\mu \mathrm{g} / \mathrm{mg})$ & Seeds $(\mu \mathrm{g} / \mathrm{mg})$ \\
\hline Arg & $0.16 \pm 0.01 / 0.21 \pm 0.01 *$ & $0.01 \pm 0.00 / 0.01 \pm 0.00$ & $0.73 \pm 0.01 / 0.71 \pm 0.04$ \\
\hline Lys & $0.21 \pm 0.01 / 0.47 \pm 0.02 * *$ & $0.40 \pm 0.02 / 0.22 \pm 0.01 *$ & $1.46 \pm 0.05 / 1.51 \pm 0.02$ \\
\hline His & $0.02 \pm 0.00 / 0.03 \pm 0.00$ & $0.02 \pm 0.00 / 0.02 \pm 0.00$ & $0.12 \pm 0.00 / 0.15 \pm 0.01 *$ \\
\hline Asp & $0.19 \pm 0.01 / 0.22 \pm 0.01$ & $0.16 \pm 0.00 / 0.10 \pm 0.00 *$ & $1.02 \pm 0.03 / 1.02 \pm 0.03$ \\
\hline Glu & $0.12 \pm 0.00 / 0.18 \pm 0.09 *$ & $0.46 \pm 0.01 / 0.19 \pm 0.01 *$ & $1.02 \pm 0.03 / 1.08 \pm 0.04$ \\
\hline Phe & $0.04 \pm 0.01 / 0.06 \pm 0.00$ & $0.09 \pm 0.01 / 0.05 \pm 0.00 *$ & $0.18 \pm 0.01 / 0.25 \pm 0.01 *$ \\
\hline Cys & $0.01 \pm 0.00 / 0.01 \pm 0.00$ & $0.01 \pm 0.00 / 0.01 \pm 0.00$ & $0.02 \pm 0.00 / 0.02 \pm 0.00$ \\
\hline Gln & $0.16 \pm 0.00 / 0.18 \pm 0.01$ & $0.49 \pm 0.02 / 0.19 \pm 0.01^{* *}$ & $0.82 \pm 0.03 / 0.74 \pm 0.01$ \\
\hline Asn & $0.11 \pm 0.01 / 0.08 \pm 0.01$ & $0.06 \pm 0.01 / 0.03 \pm 0.00 *$ & $0.49 \pm 0.01 / 0.45 \pm 0.01$ \\
\hline Gly & $0.10 \pm 0.00 / 0.08 \pm 0.01$ & $0.07 \pm 0.00 / 0.05 \pm 0.00$ & $0.35 \pm 0.02 / 0.37 \pm 0.02$ \\
\hline Ala & $0.15 \pm 0.00 / 0.18 \pm 0.01$ & $1.14 \pm 0.06 / 0.51 \pm 0.02^{* *}$ & $3.26 \pm 0.08 / 3.49 \pm 0.14$ \\
\hline Ile & $0.02 \pm 0.00 / 0.06 \pm 0.00 *$ & $0.06 \pm 0.00 / 0.03 \pm 0.00 *$ & $0.16 \pm 0.00 / 0.29 \pm 0.01 *$ \\
\hline Leu & $0.09 \pm 0.01 / 0.14 \pm 0.03^{*}$ & $0.19 \pm 0.09 / 0.10 \pm 0.00 *$ & $0.26 \pm 0.01 / 0.29 \pm 0.01$ \\
\hline Met & $0.01 \pm 0.00 / 0.02 \pm 0.00 *$ & $0.02 \pm 0.00 / 0.01 \pm 0.00$ & $0.13 \pm 0.00 / 0.11 \pm 0.01$ \\
\hline Pro & $0.05 \pm 0.00 / 0.06 \pm 0.01$ & $0.13 \pm 0.01 / 0.08 \pm 0.03 *$ & $1.28 \pm 0.03 / 1.38 \pm 0.04$ \\
\hline Ser & $0.15 \pm 0.01 / 0.15 \pm 0.01$ & $0.26 \pm 0.01 / 0.08 \pm 0.01^{* *}$ & $0.73 \pm 0.01 / 0.70 \pm 0.01$ \\
\hline Thr & $0.06 \pm 0.01 / 0.08 \pm 0.01 *$ & $0.12 \pm 0.00 / 0.08 \pm 0.01$ & $0.39 \pm 0.02 / 0.44 \pm 0.01$ \\
\hline $\operatorname{Trp}$ & $0.03 \pm 0.00 / 0.02 \pm 0.00$ & $0.03 \pm 0.00 / 0.05 \pm 0.00$ & $0.04 \pm 0.00 / 0.06 \pm 0.00 *$ \\
\hline Tyr & $0.02 \pm 0.00 / 0.03 \pm 0.00$ & $0.04 \pm 0.00 / 0.02 \pm 0.00$ & $0.09 \pm 0.01 / 0.20 \pm 0.09 * *$ \\
\hline Val & $0.06 \pm 0.01 / 0.09 \pm 0.00 *$ & $0.15 \pm 0.01 / 0.08 \pm 0.01 *$ & $0.34 \pm 0.02 / 0.45 \pm 0.01 *$ \\
\hline Basic amino acid & $0.39 \pm 0.02 / 0.71 \pm 0.02^{* *}$ & $0.43 \pm 0.02 / 0.25 \pm 0.01^{* *}$ & $2.31 \pm 0.09 / 2.37 \pm 0.07$ \\
\hline Acidic amino acid & $0.31 \pm 0.02 / 0.40 \pm 0.02 *$ & $0.62 \pm 0.03 / 0.29 \pm 0.01^{* *}$ & $2.04 \pm 0.05 / 2.10 \pm 0.09$ \\
\hline Neutral amino acid & $1.06 \pm 0.03 / 1.24 \pm 0.03^{*}$ & $2.86 \pm 0.09 / 1.37 \pm 0.03^{* *}$ & $8.54 \pm 0.26 / 9.24 \pm 0.18 *$ \\
\hline Total amino acid & $1.76 \pm 0.05 / 2.35 \pm 0.12 * *$ & $3.91 \pm 0.08 / 1.91 \pm 0.06^{* *}$ & $12.89 \pm 0.39 / 13.71 \pm 0.21 *$ \\
\hline
\end{tabular}

\section{Discussion}

In the past decades, the members of the plant AAP family have been extensively investigated. For example, studies have shown that the amino acid transporter AAP1 could regulate the absorption and redistribution of neutral amino acids, ultimately enhancing the growth and yield of rice [24], and improving plant nitrogen use efficiency, by altering the process of the amino acid transport [37]. Furthermore, the expression and localization of amino acid transporter genes have been explored in Pisum sativum [38], the identification and expression of the AAP gene family have been investigated, at the genomic level, in 
tea plants [9], and the transport functions of AAP in rice have been reported as well [39]. Moreover, the eight genes of the AAP family in Arabidopsis, in particular AtAAP1, have been widely studied. For example, studies have shown that the AtAAP1 gene plays an important role not only in the absorption of amino acids by roots [40], but also in the transport of amino acids into the embryo, to accumulate storage protein and to increase seed yield [41]. Therefore, we further investigated the molecular functions of AtAAP1 in the transport of amino acids, in both Arabidopsis and maize plants. Specifically, Arabidopsis has been the model plant used in various plant molecular studies, due to its short life cycle and convenient maintenance, while AtAAP1 has been widely investigated due to its practical significance, showing advantageous properties in the absorption of amino acids in crops.

The expression profile of a gene is generally used to help explore the functions of the gene. In our study, we investigated the gene expression of eight AtAAP genes in WT Arabidopsis and transgenic plants with overexpression of AtAAP1. Due to the important functions that AtAAPs play in the transport of amino acids in plants [42], we further studied the change in the amino acid contents in the transgenic plants of Arabidopsis with overexpression of AtAAP1. Our results revealed that both AtAAP1 and AtAAP8 were highly expressed in the flowers and siliques, while AtAAP2, AtAAP3, and AtAAP5 were highly expressed in the leaves. The change in the expression of the eight AtAAP genes, with the overexpression of AtAAP1, was likely caused by the addition of the endosperm-specific promoter GT1. Our results were consistent with those reported previously, showing that $A A P$ genes play an important role in the acquisition of amino acids [40]. Our results revealed that the eight AtAAP genes of $A$. thaliana showed differential expression patterns in different tissues, suggesting the multifunctional specialization of these genes. Specifically, three genes (i.e., AtAAP1, AtAAP7, and AtAAP8) were significantly expressed in the flowers and siliques, whereas the expression of AtAAP5 and AtAAP6 was detected at high levels in the leaves. Studies have shown that PtAAP12, expressed in both the xylem and phloem in poplar, plays an important role in the amino acid absorption from the xylem [43]. Similarly, our study revealed that $A t A A P 6$ was expressed at high levels in the roots and siliques. These results indicate that AtAAP5 and AtAAP6 are responsible for amino acid absorption. Furthermore, studies have shown that AtAAP1 plays a critical role in the transport of amino acids to the developing embryo in A. thaliana [41]. Therefore, we speculate that both AtAAP7 and AtAAP8 genes may be also involved in the regulation of amino acid accumulation and protein storage. Studies have shown that $A t A A P 2$ may participate in the long-distance transport of amino acids in Arabidopsis [44,45]. Moreover, AtAAP3 and AtAAP6 are expressed in the vascular tissues of roots, with AtAAP3 being involved in the transport of amino acids from the apoplast to the phloem, and AtAAP6 being involved in the transport of amino acids from the xylem to the phloem [20]. The similar expression profiles of the genes AtAAP2, AtAAP3, and AtAAP4 suggest that these genes might also be responsible for the long-distance transport of amino acids.

Our results of the qRT-PCR analysis showed that the overexpression of AtAAP1 in the endosperm, led to altered expression levels of the eight $A t A A P$ genes in various tissues of the transgenic plants of $A$. thaliana (Figure 4). Based on the tissue-specific expression patterns, these eight AtAAP genes in A. thaliana, with overexpression of AtAAP1, were categorized into three groups. First, both AtAAP1 and AtAAP6 showed relatively higher expressions in both the roots and siliques than in the stems, with AtAAP1 up-regulated by 25 times and 20 times in the siliques and roots of transgenic $A$. thaliana, respectively. Second, four genes (i.e., AtAAP2, AtAAP3, AtAAP4, and AtAAP5) showed relatively high expression in the stems and siliques. Third, AtAAP7 and AtAAP8 were highly expressed in the stems and roots. These differential expression patterns were further investigated, based on the amino acid affinity analysis.

In general, the amino acid transporters that are expressed in the roots can uptake amino acids in the roots, but not accumulate amino acids. This is supported by the results reported previously, showing that the accumulation of amino acids was not achieved by the 
overexpression of VfAAP1 [21], whereas the introduced nitrogen can be easily incorporated into the proteins, without causing accumulation of amino acids [37]. Furthermore, Tegeder et al. [25] isolated PSAAP1 and PSAAP2 genes from pea cotyledons, and found that PSAAP1 was mainly expressed in the vegetative organs and embryos, while the overexpression of PSAAP1 in pea improved the nitrogen absorption and utilization efficiency, ultimately increasing the seed yield in transgenic pea plants [46]. However, the expression of PSAAP2 was not detected in any tissues. Furthermore, Garneau et al. [47] reported that PSAAP6 was expressed in the nodules of pea plants and was responsible for the transport of amino acids, assimilated by nodules to other organs, while PSAAP6 was also expressed in the roots of pea plants, affecting the nitrogen supply in both the roots and shoots. In our study, the endosperm-specific promoter GT1 was applied to enhance the expression of AtAAP1 in the roots, demonstrating the capability of the amino acid transporter AtAAP1 to transiently increase the absorption of amino acids in the roots. Furthermore, our results showed that the AtAAP1 gene was overexpressed in the siliques of both the WT and transgenic A. thaliana plants, ultimately causing the increased contents of amino acids and protein storage in seeds during the mature period. These results were in accordance with those reported previously, showing that the utilization of organic nitrogen was improved in plants with overexpression of the AtAAP1 gene, in corn plants [37].

Our results revealed that the AtAAP1 gene showed varied affinity for the 20 amino acids. These results were consistent with those reported previously, on the functions of $A A P$ genes [48,49]. Specifically, the AtAAP1 gene was mainly responsible for the absorption and transport of neutral amino acids, showing a strong affinity for Ala, Cys, Asn, Gln, Ser, and Thr, but not participating in the uptake of acidic amino acids. In comparison with the WT, the contents of many amino acids in the vegetative organs (i.e., roots, stems, and leaves) of the transgenic $A$. thaliana plants decreased with varied amounts, while the contents of most amino acids (e.g., Ala, Cys, Asn, Gln, Ser, and Thr) in the siliques increased. Similar results have been reported on the selection of amino acid substrates by AtAAP1 [40], probably caused by the strong affinity of $A t A A P 1$ for these amino acids. These results suggested that the overexpression of the AtAAP1 gene, driven by the endosperm-specific promoter, led to the accumulation of these amino acids in the siliques. Similarly, studies on the substrate specificity in Brassica rapa revealed that AtAAP1 showed different absorption capabilities of different amino acids [50], while AtAAP6 showed high affinity for most amino acids, in particular the neutral and acidic amino acids [51].

Studies have shown that AtAAP1 is expressed in both flowers and developing seeds, associated with the transport of amino acids in $A$. thaliana, further improving the plant development and the amount of storage proteins [52,53]. Similar results were also revealed in our study. Furthermore, previous studies showed that AtAAP1 played important roles in amino acid absorption from the apoplast into embryonic cells [54]. Both the substrate and tissue specificities of the transport by AtAAPs affect the quality and quantity of amino acid absorption [52]. Our results were consistent with those reported previously, showing that the overexpression of $A t A A P 1$, regulated by the endosperm-specific promoter, altered the absorption of amino acids, ultimately changing the contents of free amino acids in various tissues and organs in plants of Arabidopsis, at their mature stage [52].

Studies have shown that the expression of AtAAP1 was detected in the outer epidermal cells and parenchyma cells in the endosperm of $A$. thaliana [54], while the expression of the $A A P 1$ gene was localized in the cotyledon epidermis and parenchyma cells in both beans and peas [38]. In our study, we investigated the functions of AtAAP1 on amino acid absorption, by biochemical analyses of transgenic plants with overexpression of AtAAP1. The contents of total free amino acid and total nitrogen significantly increased in the reproductive organs (i.e., siliques) of transgenic plants. The overexpression of $A A P 1$ in the endosperm evidently increased the contents of amino acids and protein storage transported into the reproductive organs, resulting in the relatively decreased contents of amino acids and protein storage in the vegetative organs. These results were consistent with those based on the transgenic maize plants with the overexpression of $A t A A P 1$, i.e., the contents of 
amino acids in the reproductive organs of transgenic AtAAP1 maize plants were generally greater than those in the vegetative organs at their mature stage. Furthermore, in the ataap 8 mutant plants of Arabidopsis, the number of seeds was reduced by $\sim 50 \%$ and the amino acid composition in the seeds was also altered [55]. These results suggested that the endosperm-specific promoter can specifically increase the contents of amino acids in seeds and improve the effective utilization of nitrogen in crops [56]. These results were also consistent with those reported previously, with the overexpression of $A A P 1$, to increase the amount of storage protein in seeds [37,43,57].

\section{Conclusions}

In our study, the tissue-specific expression patterns of the $A t A A P$ gene family in $A$. thaliana were investigated using qRT-PCR, to explore the functions of the AtAAP genes in the transport of amino acids. The results revealed differential expression patterns of eight AtAAP genes in different tissues, showing varied absorption capacities for different amino acids, by AtAAP1, and increased acid amino contents in the reproductive organs. These results were verified in transgenic maize plants with overexpression of AtAAP1, revealing higher amino acid contents in the reproductive organs than those of the vegetative organs. Our study clearly demonstrated that the endosperm-specific promoter increased the amino acid contents in the reproductive organs and improved the effective utilization of organic nitrogen in plants, providing important evidence to support the functions of AtAAP genes in $A$. thaliana, and to further explore their roles in plant growth and development. Our study has set up the solid theoretical foundation for future investigations on improving the effective utilization of organic nitrogen by AAPs in crops.

Author Contributions: Conceptualization, Z.C. and X.C.; methodology, Z.C., Y.Z. (Yingying Zhang) and X.C.; software, J.Z. and B.F.; validation, Z.C. and X.C.; formal analysis, Z.C. and X.C.; investigation, Y.Z. (Ying Zhou), J.Z. and B.F.; resources, X.C.; data curation, Z.C. and X.C.; writing-original draft preparation, Z.C. and X.C.; writing-review and editing, Z.C. and X.C.; visualization, Z.C. and X.C.; supervision, X.C.; project administration, X.C.; funding acquisition, X.C. All authors have read and agreed to the published version of the manuscript.

Funding: This research was funded by the Key Research Project of Science and Technology Department of Jilin Province (No. 20130206012) and the Natural Science Foundation of Jilin Province (No. 20180101026JC). The APC was funded by X.C.

Acknowledgments: We would like to thank Yue $\mathrm{Xu}$ for her technical support in this study.

Conflicts of Interest: The authors declare no conflict of interest.

\section{References}

1. Chen, K.E.; Chen, H.Y.; Tseng, C.S.; Tsay, Y.F. Improving nitrogen use efficiency by manipulating nitrate remobilization in plants. Nat. Plants 2020, 6, 1126-1135. [CrossRef]

2. Walch, L.P.; Filleur, S.; Gan, Y.; Forde, B.G. Signaling mechanisms integrating root and shoot responses to changes in the nitrogen supply. Photosynth. Res. 2005, 83, 239-250. [CrossRef] [PubMed]

3. Miller, A.J.; Shen, Q.; Xu, G. Freeways in the plant: Transporters for N, P and S and their regulation. Curr. Opin. Plant Biol. 2009, 12, 284-290. [CrossRef] [PubMed]

4. Nunes, N.A.; Fernie, A.R.; Stitt, M. Metabolic and signaling aspects underpinning the regulation of plant carbon nitrogen interactions. Mol. Plant 2010, 3, 973-996. [CrossRef] [PubMed]

5. Jack, D.L.; Yang, N.M.; Saier, M.H. The drug/metabolite transporter superfamily. Eur. J. Biochem. 2001, 268, 3620-3639. [CrossRef] [PubMed]

6. $\quad$ Liang, W.; Ling, L.; Wang, M.; Du, B.; Guo, C.; Duan, Y.; Song, P.; Zhang, L.; Li, P.; Ma, J.; et al. Genome-wide identification and expression analysis of the AAAP family in Fragaria vesca. Biotechnol. Biotechnol. Eq. 2020, 34, 790-799. [CrossRef]

7. Pratelli, R.; Pilot, G. Regulation of amino acid metabolic enzymes and transporters in plants. J. Exp. Bot. 2014, 65, 5535-5556. [CrossRef]

8. Taylor, M.R.; Reinders, A.; Ward, J.M. Transport Function of Rice Amino Acid Permeases (AAPs). Plant Cell. Physiol. 2015, 56, 1355-1363. [CrossRef] 
9. Duan, Y.; Zhu, X.; Shen, J.; Xing, H.; Zou, Z.; Ma, Y.; Wang, Y.; Fang, W. Genome-wide identification, characterization and expression analysis of the amino acid permease gene family in tea plants (Camellia sinensis). Genomics 2020, 112, 2866-2874. [CrossRef]

10. Zhang, L.; Garneau, M.G.; Majumdar, R.; Grant, J.; Tegeder, M. Improvement of pea biomass and seed productivity by simultaneous increase of phloem and embryo loading with amino acids. Plant J. 2015, 81, 134-146. [CrossRef]

11. Boorer, K.J.; Fischer, W.N. Specificity and stoichiometry of the Arabidopsis H+/amino acid transporter AAP5. J. Biol. Chem. 1997, 272, 13040-13046. [CrossRef] [PubMed]

12. Boorer, K.J.; Frommer, W.B.; Bush, D.R.; Kreman, M.; Loo, D.D.; Wright, E.M. Kinetics and specificity of a H+/ amino acid transporter from Arabidopsis thaliana. J. Biol. Chem. 1996, 271, 2213-2220. [CrossRef] [PubMed]

13. Frommer, W.B.; Hummel, S.; Riesmeier, J.W. Expression cloning in yeast of a cDNA encoding a broad specificity amino acid permease from Arabidopsis thaliana. Proc. Natl. Acad. Sci. USA 1993, 90, 5944-5948. [CrossRef] [PubMed]

14. Koch, W.; Kwart, M.; Laubner, M.; Heineke, D.; Stransky, H.; Frommer, W.B.; Tegeder, M. Reduced amino acid content in transgenic potato tubers due to antisense inhibition of the leaf $\mathrm{H}+$ /amino acid symporter StAAP1. Plant J. 2003, 33, 211-220. [CrossRef]

15. Elashry, A.; Okumoto, S.; Siddique, S.; Koch, W.; Kreil, D.P.; Bohlmann, H. The AAP gene family for amino acid permeases contributes to development of the cyst nematode Heterodera schachtii in roots of Arabidopsis. Plant Physiol. Biochem. 2013, 70, 379-386. [CrossRef]

16. Joshi, V.; Joung, J.G.; Fei, Z.; Jander, G. Interdependence of threonine, methionine and isoleucine metabolism in plants: Accumulation and transcriptional regulation under abiotic stress. Amino Acids 2010, 39, 933-947. [CrossRef] [PubMed]

17. Miranda, M.; Borisjuk, L.; Tewes, A.; Heim, U.; Sauer, N.; Wobus, U.; Weber, H. Amino acid permeases in developing seeds of Vicia faba L.: Expression precedes storage protein synthesis and is regulated by amino acid supply. Plant J. 2001, 28, 61-71. [CrossRef]

18. Marella, H.H.; Nielsen, E.; Schachtman, D.P.; Taylor, C.G. The amino acid permeases AAP3 and AAP6 are involved in root-knot nematode parasitism of Arabidopsis. Mol. Plant Microbe Interact. 2013, 26, 44-54. [CrossRef]

19. Hunt, E.; Gattolin, S.; Newbury, H.J.; Bale, J.S.; Tseng, H.M.; Barrett, D.A.; Pritchard, J. A mutation in amino acid permease AAP6 reduces the amino acid content of the Arabidopsis sieve elements but leaves aphid herbivores unaffected. J. Exp. Bot. 2010, 61, 55-64. [CrossRef]

20. Okumoto, S.; Koch, W.; Tegeder, M.; Fischer, W.N.; Biehl, A.; Leister, D.; Stierhof, Y.D.; Frommer, W.B. Root phloem-specific expression of the plasma membrane amino acid proton co-transporter AAP3. J. Exp. Bot. 2004, 55, 2155-2168. [CrossRef]

21. Rolletschek, H.; Hosein, F.; Miranda, M.; Heim, U.; Götz, K.P.; Schlereth, A.; Borisjuk, L.; Saalbach, I.; Wobus, U.; Weber, H. Ectopic expression of an amino acid transporter (VfAAP1) in seeds of Vicia narbonensis and pea increases storage proteins. Plant Physiol. 2005, 137, 1236-1249. [CrossRef]

22. Tegeder, M.; Ward, J.M. Molecular evolution of plant AAP and LHT amino acid transporters. Front. Plant Sci. 2012, 3, 21 [CrossRef]

23. Hirner, A.; Ladwig, F.; Stransky, H.; Okumoto, S.; Keinath, M.; Harms, A.; Frommer, W.B.; Koch, F. Arabidopsis LHT1 is a high-affinity transporter for cellular amino acid uptake in both root epidermis and leaf mesophyll. Plant Cell 2006, 18, 1931-1946. [CrossRef]

24. Ji, Y.Y.; Huang, W.T.; Wu, B.W.; Fang, Z.M.; Wang, X.L. The amino acid transporter AAP1 mediates growth and grain yield by regulating neutral amino acid uptake and reallocation in Oryza sativa. J. Exp. Bot. 2020, 71, 4763-4777. [CrossRef]

25. Tegeder, M.; Offler, C.E.; Frommer, W.B.; Patrick, J.W. Amino acid transporters are localized to transfer cells of developing pea seeds. Plant Physiol. 2000, 122, 319-325. [CrossRef] [PubMed]

26. Fan, B.; Liu, M.; Li, H.; Zhang, X.; Wang, X.; Cui, X. Bioinformatics analysis of AAP gene family in Arabidopsis thaliana. Chem. Life 2015, 35, 1-8.

27. Sheng, L.; Deng, L.; Yan, H.; Zhao, Y.; Dong, Q.; Li, Q.; Li, X.; Cheng, B.; Jiang, H. A genome-wide analysis of the AAAP gene family in maize. J. Proteom. Bioform. 2014, 7, 23-33.

28. Wu, M.; Wu, S.; Chen, Z.; Dong, Q.; Yan, H.; Xiang, Y. Genome-wide survey and expression analysis of the amino acid transporter gene family in poplar. Tree Genet. Genomes 2015, 11, 83. [CrossRef]

29. Li, H.J. Functional Characterization of Arabidopsis Amino Acid Permease 1 (AtAAP1) in Transgenic Maize. MS Thesis, Jilin Agricultural University, Changchun, Jilin, China, 2017.

30. Bates, L.S.; Waldren, R.P.; Teare, I.D. Rapid determination of free proline for water-stress studies. Plant Soil 1973, 39, 205-207. [CrossRef]

31. Zhang, Q.F.; Qi, D.M.; Dong, X.B.; Li, X.X.; Cheng, L.Q.; Liu, H.; Chen, S.Y.; Rajora, O.P.; Li, X.Q.; Liu, G.S. Amino acid composition, protein content and accurate nitrogen-to-protein conversion factor for sheepgrass (Leymus chinensis). Botany 2020, 98, 137-146. [CrossRef]

32. Bonner, C.A.; Jensen, R.A. Recognition of specific patterns of amino acid inhibition of growth in higher plants, uncomplicated by glutamine-reversible general amino acid inhibition. Plant Sci. 1997, 130, 133-143. [CrossRef]

33. Voll, L.M.; Allaire, E.E.; Fiene, G.; Weber, A.P.M. The Arabidopsis phenylalanine insensitive growth mutant exhibits a deregulated amino acid metabolism. Plant Physiol. 2004, 136, 3058-3069. [CrossRef] [PubMed] 
34. Chen, Z.Y.; Fang, X.K.; Yuan, X.S.; Zhang, Y.Y.; Li, H.Y.; Zhou, Y.; Cui, X.Y. Overexpression of transcription factor GmTGA15 enhances drought tolerance in transgenic soybean hairy roots and Arabidopsis plants. Agronomy 2021, 11, 170. [CrossRef]

35. Livak, K.J.; Schmittgen, T.D. Analysis of relative gene expression data using real-time quantitative PCR and the 2(-Delta Delta C(T) ) method. Methods 2001, 25, 402-408. [CrossRef]

36. Tang, Q.Y.; Zhang, C.X. Data processing system (DPS) software with experimental design, statistical analysis and data mining developed for use in entomological research. Insect Sci. 2012, 20, 254-260. [CrossRef] [PubMed]

37. Liu, S.; Wang, D.; Mei, Y.; Xia, T.; Xu, W.; Zhang, Y.; You, X.; Zhang, X.; Li, L.; Ning, N. Overexpression of GmAAP6a enhances tolerance to low nitrogen and improves seed nitrogen status by optimizing amino acid partitioning in soybean. Plant Biotechnol. J. 2020, 8, 1749-1762. [CrossRef]

38. Tegeder, M.; Tan, Q.; Grennan, A.K.; Patrick, J.W. Amino acid transporter expression and localisation studies in pea (Pisum sativum). Funct. Plant Biol. 2007, 34, 1019-1028. [CrossRef] [PubMed]

39. Zhou, T.; Yue, C.; Huang, J.; Cui, J.; Liu, Y.; Wang, W.; Tian, C.; Hua, Y. Genome-wide identification of the amino acid permease genes and molecular characterization of their transcriptional responses to various nutrient stresses in allotetraploid rapeseed BMC Plant Biol. 2020, 20, 151. [CrossRef]

40. Lee, Y.H.; Foster, J.; Chen, J.; Voll, L.M.; Weber, A.P.M.; Tegeder, M. AAP1 transports uncharged amino acids into roots of Arabidopsis. Plant J. 2007, 50, 305-319. [CrossRef]

41. Sanders, A.; Collier, R.; Trethewy, A.; Gould, G.; Sieker, R.; Tegeder, M. AAP1 regulates import of amino acids into developing Arabidopsis embryos. Plant J. 2009, 59, 540-552. [CrossRef]

42. Dinkeloo, K.; Boyd, S.; Pilot, G. Update on amino acid transporter functions and on possible amino acid sensing mechanisms in plants. Semin. Cell Dev. Biol. 2018, 74, 105-113. [CrossRef] [PubMed]

43. Couturier, J.; De, F.E.; Fitz, M.; Wipf, D.; Blaudez, D.; Chalot, M. PtAAP11, a high affinity amino acid transporter specifically expressed in differentiating xylem cells of poplar. J. Exp. Bot. 2010, 61, 1671-1682. [CrossRef]

44. Hirner, B.; Fischer, W.N.; Rentsch, D.; Kwart, M.; Frommer, W.B. Developmental control of $\mathrm{H}^{+}$/amino acid permease gene expression during seed development of Arabidopsis. Plant J. 1998, 14, 535-544. [CrossRef]

45. Okumoto, S.; Pilot, G. Amino acid export in plants: A missing link in nitrogen cycling. Mol. Plant 2011, 4, 453-463. [CrossRef]

46. Perchlik, M.; Tegeder, M. Improving plant nitrogen use efficiency through alteration of amino acid transport processes. Plant Physiol. 2017, 175, 235-247. [CrossRef]

47. Garneau, M.G.; Tian, Q.; Tegeder, M. Function of pea amino acid permease AAP6 in nodule nitrogen metabolism and export, and plant nutrition. J. Exp. Bot. 2018, 69, 5205-5219. [CrossRef] [PubMed]

48. Pan, X.; Hasan, M.M.; Li, Y.; Liao, C.; Zheng, H.; Liu, R.; Li, X. Asymmetric transcriptomic signatures between the cob and florets in the maize ear under optimal- and low-nitrogen conditions at silking, and functional characterization of amino acid transporters ZmAAP4 and ZmVAAT3. J. Exp. Bot. 2015, 66, 6149-6166. [CrossRef]

49. Tan, Q.; Grennan, A.K.; Pélissier, H.C.; Rentsch, D.; Tegeder, M. Characterization and expression of French bean amino acid transporter PvAAP1. Plant Sci. 2008, 174, 348-356. [CrossRef]

50. Tilsner, J.; Kassner, N.; Struck, C.; Lohaus, G. Amino acid contents and transport in oilseed rape (Brassica napus L.) under different nitrogen conditions. Planta 2005, 221, 328-338. [CrossRef]

51. Fischer, W.N.; André, B.; Rentsch, D.; Krolkiewicz, S.; Tegeder, M.; Breitkreuz, K.; Frommer, W.B. Amino acid transport in plants Trends Plant Sci. 1998, 5, 188-195. [CrossRef]

52. Fischer, W.N.; Kwart, M.; Hummel, S.; Frommer, W.B. Substrate specificity and expression profile of amino acid transporters (AAPs) in Arabidopsis. J. Biol. Chem. 1995, 270, 16315-16320. [CrossRef]

53. Ren, Z.; Chen, Z.; Luo, X.; Su, J.; Yao, G.; Xu, H.; Lin, F. Overexpression of AtAAP1 increased the uptake of an alaninechlorantraniliprole conjugate in Arabidopsis thaliana. Environ. Sci. Pollut. Res. Int. 2019, 26, 36680-36687. [CrossRef] [PubMed]

54. Guo, M.J. Molecular and Genomic Analysis of Nitrogen Regulation of Amino Acid Permease I (AAP1) in Arabidopsis. Ph.D. Thesis, University of Illinois at Urbana-Champaign, Urbana, IL, USA, 2004.

55. Schmidt, R.; Stransky, H.; Koch, W. The amino acid permease AAP8 is important for early seed development in Arabidopsis thaliana. Planta 2007, 226, 805-813. [CrossRef] [PubMed]

56. Liu, X.; Zhang, C.; Wang, X.; Liu, Q.; Yuan, D.; Pan, G.; Sun, S.S.M.; Tu, J. Development of high-lysine rice via endosperm-specific expression of a foreign LYSINE RICH PROTEIN gene. BMC Plant Biol. 2016, 16, 147. [CrossRef]

57. Manoela, M.; Ljudmilla, B.; Annegret, T.; Daniela, D.; Doris, R.; Hans, W.; Ulrich, W. Peptide and amino acid transporters are differentially regulated during seed development and germination in faba bean. Plant Physiol. 2003, 132, $1950-1960$. 